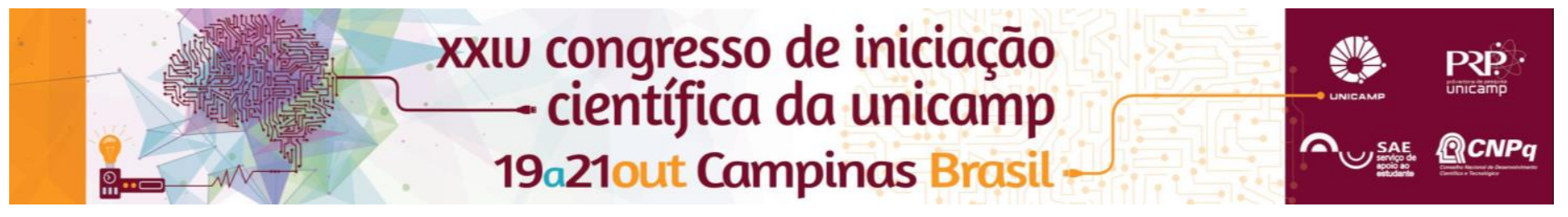

\title{
Determinantes da escolha do modal não-motorizado de transporte e políticas públicas
}

\author{
Eduardo Dias Dini, Alexandre Gori Maia, Cristiane Silva de Carvalho
}

\begin{abstract}
Resumo
Frente a insustentabilidade dos modelos de políticas públicas centrados no transporte individual motorizado, foi promulgada a Lei da Política Nacional de Mobilidade Urbana em 2012 fundamentada nos princípios de acessibilidade universal, desenvolvimento sustentável e gestão democrática ${ }^{1}$, colocando o transporte não-motorizado (caminhada e bicicleta) em foco na gestão da política urbana municipal. A pesquisa consiste em uma revisão da literatura relacionada às formas não-motorizadas de transporte e entrevista com gestor de mobilidade urbana da cidade de Sorocaba, referência nacional no transporte cicloviário.
\end{abstract}

\section{Palavras-chave \\ Transporte não-Motorizado, Políticas Públicas, Determinantes de Escolha}

\section{Introdução \\ Em 2012 foi promulgada a Lei $\mathrm{N}^{\circ} 12.587$ que} institui a Política Nacional de Mobilidade Urbana que define a competência de cada órgão federativo quanto a Mobilidade Urbana. Seu objetivo é contribuir com o acesso universal à cidade, e suas diretrizes norteadoras são priorizar o transporte não-motorizado sobre o motorizado e o transporte público sobre o individual ${ }^{1}$.

Medidas de promoção do transporte nãomotorizado são bastante comuns na Europa, e se tornaram tema de discussão na América do Norte recentemente dada a insustentabilidade do modelo urbano de subúrbios; no Brasil, com a instituição da Lei $N^{\circ} 12.587$ prevê que todas as cidades com mais de 20 mil habitantes elaborem seus Planos de Mobilidade Urbana, até então eram poucas as cidades que consideravam o transporte não-motorizado como uma forma relevante de modal e possuía políticas públicas com o objetivo de aumentar esta parcela.

O trabalho tem como objetivo a revisão da literatura de políticas públicas em prol do transporte nãomotorizado, com posterior entrevista com gestor de mobilidade urbana da cidade de Sorocaba. Dessa forma espera-se contribuir para orientar políticas públicas de promoção de um sistema de transporte de baixo carbono.

\section{Resultados e Discussão}

Os meios não-motorizados são vistos como a solução para problemas de mobilidade urbana nas grandes e médias cidades². Mas para que haja um uso efetivo da bicicleta como meio de transporte nas grandes e médias cidades é demandada uma infraestrutura básica para o usuário, como rotas seguras, sinalização exclusiva, redução da velocidade médias dos veículos motorizados em algumas zonas da cidade, estacionamentos para bicicletas e vestuários nos locais de destino ${ }^{3}$. Além da infraestrutura, é destacado a mobilização democrática participativa como parte do processo, sendo importante que a população aceite, defenda e reivindique as mudanças na infraestrutura urbana ${ }^{4}$.

Segundo o Ministério da Cidades, o transporte cicloviário está bem abaixo do seu potencial, sendo disseminado em dois segmentos bem distintos: classes de renda média alta e as classes de renda muito baixas. Sendo estes últimos os grandes usuários, fazendo uso regular como modo de transporte.

DOI: 10.19146/pibic-2016-51443
A cidade de Sorocaba, no interior de São Paulo, foi escolhida como modelo para análise das ações de poder público em prol de políticas públicas que promovam formas de transporte não-motorizado, sendo referência nacional no transporte cicloviário pelo pioneirismo na construção de infraestrutura especial para bicicletas (contando com 134 quilômetros de faixas exclusivas e compartilhadas).

Foi feito um levantamento de informações e dados sobrea a cidade de Sorocaba e a sua infraestrutura cicloviária com posterior entrevista com o gestor de mobilidade urbana da cidade. O entrevistado ressaltou a importância do comprometimento político com o desenvolvimento das medidas e diretrizes e a participação da sociedade civil na construção de um Plano de Mobilidade consistente. Mas, apesar da infraestrutura notável, o uso do sistema como modo de transporte de uso regular ainda é baixo, com destaque ao uso para fins recreativos.

\section{Conclusões}

Com base na análise da bibliografia e os insumos dados pela entrevista feita, fica clara a importância do comprometimento político com o desenvolvimento de uma infraestrutura urbana comprometida com o transporte não-motorizado. Mas quanto a maneira de implementação, ainda é preciso de mais pesquisas e planejamento, para que essa infraestrutura alcance o máximo do seu potencial.

\section{Agradecimentos}

Ao professor e orientador Alexandre Gori Maia pelo apoio e paciência durante todo o processo de pesquisa, e à Cristiane Carvalho que nos acompanhou e também teve importante papel de orientação. À Unicamp e ao Pibic/CNPq pela concessão da bolsa e pelo incentivo à produção científica dos alunos de graduação.

\footnotetext{
1 MINISTÉRIO DAS CIDADES, 2012. Política Nacional de Mobilidade Urbana.

${ }^{2}$ XAVIER, G. N. A. O desenvolvimento e a inserção da bicicleta na Política de Mobilidade Urbana Brasileira. Florianópolis, 2011. Tese de Doutorado. Centro de Filosofia e Ciências Humanas, UFSC.

3 FERNÁNDEZ-HEREDIA, Alvaro, et al. 2014. "Understanding Cyclists' Perceptions, Key for a Succesful Bicycle Promotion." Transportation Research Part A Policy and Practice 63 1-11.

4 CHAPADEIRO, F.C. Limites e potencialidades do planejamento cicloviário: um estudo sobre a participação cidadã. Brasília, 2011. Tese. Faculdade de Tecnologia, Universidade de Brasília.
} 